\title{
Paleovariability: Data Model Comparisons
}

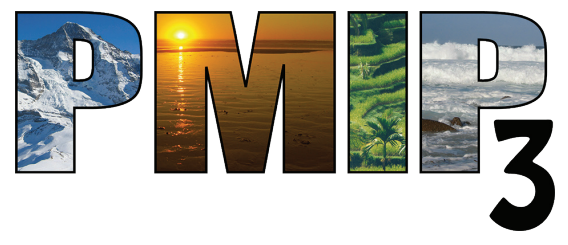

Chris Brierley ${ }^{1}$ and Kira Rehfeld ${ }^{2}$

London, UK, 12-14 March 2014

Past global changes provide a useful test for evaluating climate models. With modeling efforts increasingly focused on decadal predictions and climate services, there is a growing need to evaluate simulated climate variability. Past climates offer some opportunity for this, but require a slightly different approach than those currently adopted to look at mean changes. University College London's Geography department hosted a three-day workshop to explore the issues associated with paleoclimate variability.

In some respects, this workshop emerged in response to the problems discovered during a previous PAGES-supported workshop focused on the El Niño-Southern Oscillation (ENSO; Braconnot et al. 2012). Coming out of this workshop, two requirements were identified as pivotal to model evaluation using PaleoENSO: (i) a more integrated approach across regions and disciplines, and (ii) the development of statistical and analytical tools to enable that intercomparison.

A special issue of PAGES news dedicated to ENSO highlighted recent advances across the ENSO regions and disciplines with the aim of kick-starting this more integrated approach (Braconnot et al. 2013). It was recognized that a dedicated activity is required to effectively tackle the two requirements - which are relevant for all modes of climate variability, rather than just ENSO.

In response, a working group on variability was established under the auspices of the Paleoclimate Modelling Intercomparison Project (PMIP3); this workshop was its first meeting. The focus of this meeting was on variability on inter-annual to multi-decadal timescales, in part because on longer timescales models appear to underestimate variability (Laepple and Huybers 2014). It was established that variability comparisons suffer additional difficulties compared with conventional analyses for the mean state.

Indeed, intermediate processing is often required between the models and data, which is its own field of expertise. Some of this intermediate processing relates to forward proxy modeling, represented at the workshop by efforts to model lake isotopic systems (Jones and Imbers 2010). The rest relates to how proxy properties impact a record's statistics - for example looking at the impact of sampling individual forams (Thirumalai et al. 2013) or seasonal biases (Laepple and Huybers 2013).

One conclusion was an appreciation that additional meta-data is often required to use a

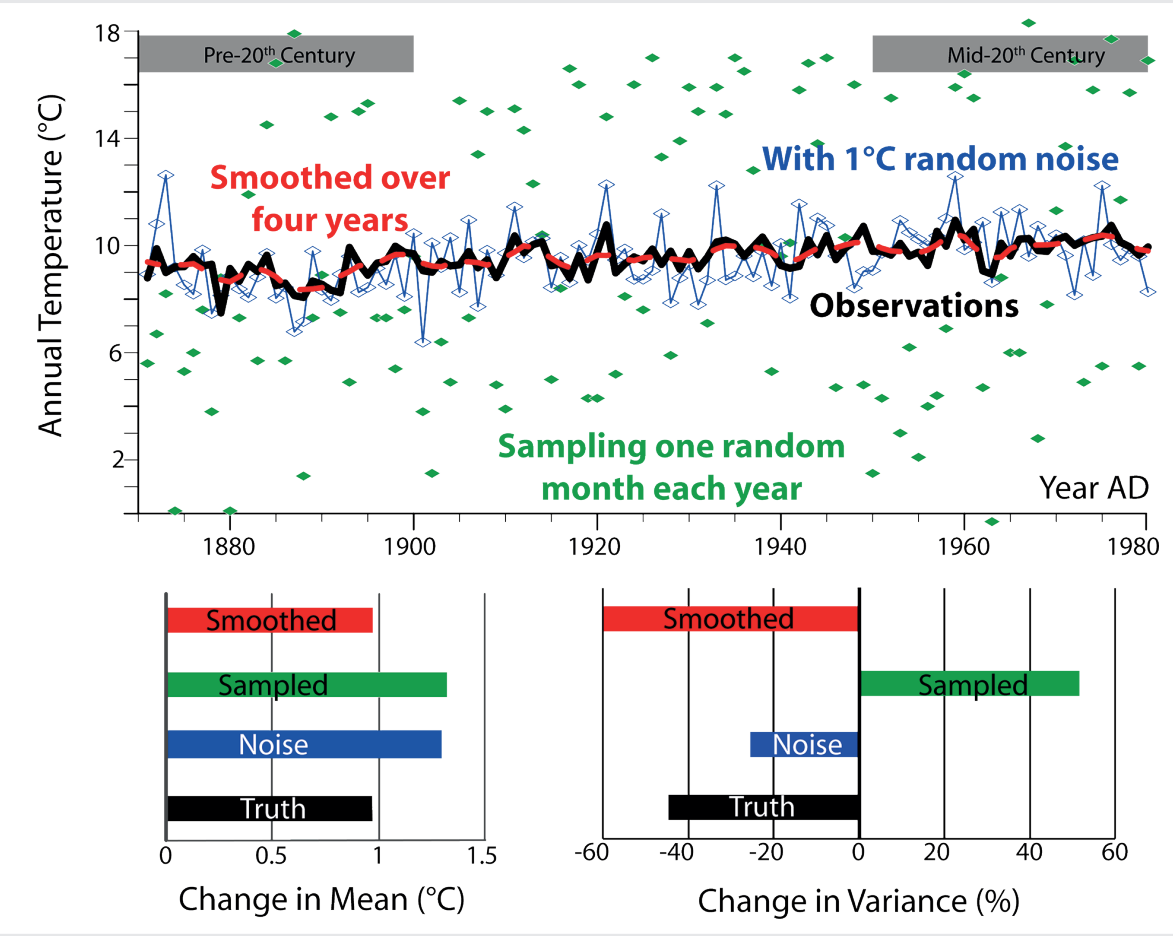

Figure 1: Annual temperatures measured at Kew Gardens, London (Peterson and Vose 1997) as an example of the three potential factors' impacting climate variability. Neither adding random noise (e.g. instrumental error), nor smoothing (e.g. bioturbation), nor snapshot-type sampling (e.g. individual organisms that only live for a single random month) substantially alters the roughly $1^{\circ} \mathrm{C}$ of warming; however, the normalized estimates of variability differ in both magnitude and even sign.

proxy-climate record for variability data model comparisons. This additional information is needed to understand how the individual measurements relate to each other. This becomes much more important for studies of paleoclimate variability than when looking at mean changes, as illustrated with the example of London annual temperatures (Fig. 1). We urge people to consider the following three questions when publishing a proxy record:

- To what extent are your stated errors
random?

- Does each sample represent a time-average or a snapshot?

- Is the effective temporal resolution lower than the sampling resolution (e.g. through bioturbation or residence times prior to sedimentation)?

Practically speaking, for large proxy syntheses it is important that age modeling and calibration are replicable. This requires access to the proxy dataset (including depths, proxy measurements and sample size), the age modeling information (i.e. age estimates and errors with their depths), and the calibration information, as well as knowledge of the sampling strategy and proxy processes.
In summary, to obtain reliable and comparable estimates of past climatic variability, we must correct for the additional processes affecting proxy variability. This is not an easy task: it requires input from several disciplines, but has the potential to be much more relevant for the coming decades than studies of mean climate alone.

\section{AFFILIATIONS}

${ }^{1}$ University College London, UK

${ }^{2}$ Alfred Wegener Institute, Helmholtz Centre for Polar and Marine Research, Potsdam, Germany

\section{CONTACT}

Chris Brierley: c.brierley@ucl.ac.uk

\section{REFERENCES}

Full reference list under:

www.pages-igbp.org/products/magazine/ref2014_2.pdf

Braconnot P et al. (2013) PAGES news 21: 48-49

Jones MD, Imbers J (2010) Global Planet Change 71: 193-200

Laepple T, Huybers PJ (2014) Geophys Res Lett 41: 2528-2534

Laepple T, Huybers PJ (2013) Earth Planet Sci Lett 375: 418-429

Thirumalai K et al. (2013) Paleoceanogr 28: 401-412 